\title{
Research on the "Multi-network Synergy" Governance Path of Food Safety in China
}

\author{
Li Jing, Shen Liting \\ School of Public Administration, Hohai University, Nanjing, China \\ Email address: \\ yanjing721@sina.com (Li Jing), shenliting1126@qq.com (Shen Liting)
}

\section{To cite this article:}

Li Jing, Shen Liting. Research on the "Multi-network Synergy" Governance Path of Food Safety in China. International Journal of Nutrition and Food Sciences. Vol. 8, No. 5, 2019, pp. 71-77. doi: 10.11648/j.ijnfs.20190805.11

Received: March 20, 2019; Accepted: July 25, 2019; Published: December 6, 2019

\begin{abstract}
Food safety is an important issue related to people's livelihood. In recent years, with the government's high attention, the food safety situation has improved slightly, but there are still many problems, and food safety incidents occur frequently. Through investigation and analysis, it is found that the current regulatory system presents "multi-head mixed management" in the main design, "one-way and one-dimensional" in the structure design, and "subsection supervision" in the operation mechanism. These drawbacks seriously affect the effectiveness of supervision. It is necessary to reconstruct China's food safety governance system, giving full play to the functions of government leaders, corporate responsibility and public beneficiaries; making full use of trust mechanism and collaboration mechanism to construct a multi-dimensional network system; and in the design of operational mechanism, promoting multi-dimensional collaboration by clarifying responsibilities, improving technology and information disclosure.
\end{abstract}

Keywords: Food Safety, Supervision Mechanism, Policy Coupling, Multiple Network Co-Governance

\section{Introduction: Perfecting Food Safety Supervision Mechanism Is Urgent}

In the most basic sense, in order to promote social development and improve human well-being, the first condition is to maintain and guarantee the health and safety of the people's lives, and to achieve this condition, government must effectively guarantee food safety and ensure the improvement of people's living standards with the supply of safe food. Therefore, it can be said that the issue of food safety concerns the vital interests of the broad masses of the people and the safety of life and property, the overall well-off and overall harmony of society, the sustained, healthy and rapid development of the national economy, the credibility and legitimacy of the party and the government. Safeguarding food safety has become a basic requirement for the Chinese government to fulfill its supervisory duties and safeguard the interests of the people.

Since entering the 21 st century, many serious food safety problems have broken out in China. The main social contradictions in the field of food have been upgraded from the contradictions of quantity and hygiene to the contradictions of quality and safety [1]. This has seriously affected the stability and healthy development of society, and has produced a series of adverse effects. On the one hand, food safety issues have damaged the health of the people and their consumer confidence. On the other hand, food safety issues have undermined market order and have had a huge impact on related industries. It is precisely because food safety issues are related to the health of consumers, often resulting in major economic losses, easy to cause international trade disputes, and therefore widely concerned around the world [2]. In view of this, how to perfect China's food safety supervision mechanism, innovate food safety supervision mode, improve food safety supervision performance, and effectively protect food safety has become an urgent issue facing the theoretical and practical circles.

It is precisely because of the extreme importance of food safety in national life that the Chinese government has always attached great importance to the supervision of food safety production and circulation. 


\section{Analysis on the Current Situation of Food Safety Supervision Mechanism in China}

It is based on the vital importance of food safety in national life that the Chinese government has always attached great importance to the supervision of food safety production and circulation. Generally speaking, China's current food safety supervision mechanism is a "unitary one -way piecewise paradigm", that is, as far as the management subject is concerned, it is a one-dimensional design with the government as the absolute subject; and as far as the architecture of management is concerned, it is a one-way and one-dimensional structure design from top to bottom, from the government to enterprises, from the government to consumers and from the government to the society under the regulation of the government. In terms of the mechanism of management mode, it is the compete for power slander responsibility mechanism on the basis of segmented supervision, or the segmented supervision mechanism under the interest game pattern.

\subsection{Main Design: The System of Unitary with "Mixed Governance"}

Based on China's complex interests and the traditional "big government, small society" social structure, government departments have always been in an absolute dominant position in food safety management. Since the beginning of the 21 st century, in the face of the increasingly severe security situation, although the relevant regulatory departments have undergone many adjustments, most of them focus on the adjustment of the government's institutional settings and functional allocation, which is carried out within the system of the government, forming a regulatory mechanism of "taking the sectional supervision as the main and the variety supervision as the supplement".

Through the investigation of all aspects of the food chain, it can be found that the government has been in a monist position in the social and economic affairs, including food safety supervision, due to the traditional concept of government, the highly centralized historical tradition, the inertia of the rigid planned economic system, and the influence of the intricate interests between the various departments in the chain of custody. The power of social subjects such as trade associations, news media and third party testing institutions has not received sufficient attention and full play.

Is it because other subjects lack motivation to participate that the government is dominant? In order to study the actual situation of consumers ' participation in food safety management, the author led the research team to conduct field research by means of questionnaire survey in Kunming, Yunnan Province from December 5, 2012 to December 25. The survey site is mainly composed of Xiaoximen, Nanping Pedestrian Street, South Asia Style First City, Dianchi College of Yunnan University, Guangfu Community and other crowded areas. A total of 1000 questionnaires were distributed, 988 were collected, and 972 valid questionnaires. After the results of the survey and the quantitative analysis, the results of the data generally reflected several cases. First, the general participation of consumers is very enthusiastic. More than $73.4 \%$ of people are willing to participate in food safety management, and only $1.3 \%$ of consumers have no willingness to participate. Second, the initiative of participation is generally high. Up to $64.7 \%$ of respondents said that they would actively pay attention to food safety information, and $79.6 \%$ of respondents said that they would take the initiative to seek help when they encounter food safety problems. As for the channels for seeking help, 27.5\% of the respondents said they would negotiate with the production operators, $22.4 \%$ said they would complain to the relevant government departments, $19.4 \%$ said they would request the consumer association to intervene in mediation, $14.2 \%$ said they would seek help from the media, $0.3 \%$ said they would submit arbitration to the arbitration body, and about $0.1 \%$ said they would sue in court, while only $16.1 \%$ of respondents said they would not take any action to protect their rights. Third, the reasons why consumers do not participate are roughly the same, mostly because of the system or mechanism and other objective reasons. There are up to $87.4 \%$ of the respondents said that it is because of the imperfect participation mechanism, the obstruction of communication channels, and the lack of obvious participation effect, which makes participation ineffective. In terms of specific data, $35.1 \%$ of respondents were reluctant to spend their energy and time complaining, 30.6\% were not aware of the complaints department, the receiving department and the complaint channel or problem Resolution, and 27.7\% considered that the complaint had no practical effect and could not solve the problem at all, and $6.6 \%$ respondents said they confessed to bad luck and pay attention next time. It is not difficult to see from the above data analysis that the main reason for the insufficient participation of Yunnan consumers in food safety governance is that the participation channels caused by institutional defects are not smooth, or the participation incentives are insufficient.

In addition, in terms of the design of participating entities, the food safety regulatory mechanism also manifests itself as the system of "unitary with the long mix governance", that is, the orderly participation and coordination between various departments within the government is insufficient. Specifically, it can be understood from two dimensions: first, there are many departments involved in food safety regulation. At present, the authority of food safety management in China belongs to agriculture, commerce, health, quality inspection, industry and commerce, environmental protection, legal system, planning and finance, which forms a situation of 'multi-head management, no one is responsible', seriously affecting the authority of supervision and law enforcement [3]. In 2013, the "super-ministries system" reform plan adopted by the National People's Congress (NPC) and Chinese People's Political Consultative Conference (CPPCC), proposed the establishment of the "Food and Drug Administration". 
Although the powers dispersed in several regulatory departments were integrated to a certain extent, the integration efforts were far from expected. It can be seen from the published scheme, only the Food Safety Office, the Food and Drug Administration, the General Administration of Quality Inspection (AQSIQ) to the supervision of the production chain, the general administration of industry and commerce to regulate the circulation of these powers to integrate. But the agriculture, health, business and other sectors of food safety supervision authority has not been involved. This simply reduces the "head" of regulation, but does not achieve "singularization" [4]. The original intention of China's implementation of food safety "piecewise supervision" is to refine the supervision duties, so that all aspects of food production, processing, transportation, sales and consumption can be fully managed and guided by the policy subjects. However, due to the limitations of the system and mechanism, in the actual operation, due to the unclear definition of authority, unclear division of duties, and interest disputes, the division of functions and political affairs have occurred frequently, which directly leads to the "mixing of governance". This is also the second dimension we understand. "Mix governance" in the field of food and medicine will not only lead to repeated investment, repeated supervision, repeated enforcement, resulting in waste of resources, but also lead to enterprises struggling to cope with repeated enforcement, not conducive to the development of the industry, and lead to excessive supervision and supervision of the adverse coexistence, resulting in inefficient supervision.

\subsection{Architectural Design: “One-Way One-Dimensional Supervision” Under the Framework of Government}

As far as the architecture design is concerned, the current supervision mechanism of food safety in China presents a typical "one-way one-dimensionality". The so-called "one-way" is mainly manifested in two aspects: on the one hand, most of them only have the supervision of the food industry by government executive agencies and the investigation of problem enterprises, which easily form the dependence of the food industry on government supervision, which weakens the supervision power of the retail enterprises on the production enterprises [5], and also lacks reverse supervision of government policies, regulatory performance, and consumer groups, social organizations, and related enterprises. On the other hand, most government departments follow the traditional "field-to-table" production model, focusing on the process of production, processing, circulation, and consumption. After the problem occurs, most of them are finding the reason for a certain part of the responsibility, lacking a food safety traceability mechanism, and rarely "reverse tracing". The so-called "one-dimensionality" mainly includes two meanings. One is the "one-dimensional" of the degree of power operation, that is, the mechanism of coordination and cooperation between the Government and other governance subjects, as well as between the various functional departments within the government is not smooth, the cooperation network between institutions has not been established. The second is the "one-dimensional" information dissemination. Most of the current food safety information is issued by the government authority, and the social feedback and communication mechanism of information is not yet perfect, and the information network needs to be improved.

At present, China's industrial and commercial, quality inspection and other systems implement vertical management. This system can maintain the authority of the central government and improve the efficiency of decision-making. However, due to the lack of strict supervision by the higher authorities and the lack of supervision by the local government, it is easy to "deviate from the objectives of the higher commissioning agencies" [6]. In addition, due to the relatively fixed staffing and mobility within the vertical management department, there is a lack of motivation, rigid organization and inadequate vitality of its internal staff, which is high likely to lead to "regulatory failure". At the same time, the establishment of food safety horizontal regulation institutions based on the "piecewise governance" model can easily lead to "collective action dilemmas" and "the tragedy of anti-commons".

\subsection{Operational Mechanism: "Segmentation Supervision" Under the Game of Interests}

Although effective measures have been taken in the aspects of institutional integration, functional coordination and partnership building, which reflect the value orientation of the whole government in a sense, the "unitary one-way piecewise supervision" mode formed after several reforms still manifests itself as "segmentation supervision" under the pattern of interest game or "power struggle and responsibility shifting" on the basis of subsection supervision as far as the operation mechanism is concerned.

The Food Safety Law, revised in 2015, has solidified the results of the food safety regulatory system reform in the form of laws, strengthened food safety supervision, and implemented the most rigorous process management for production, sales, and catering services [7]. But all previous reforms of the operational mechanism of China's current food safety supervision mechanism have focused on the integration of a specific regulatory link, on the high concentration of regulatory power in each link, on the simplification of the main body in each regulatory link, but relatively neglected the integration and coordination of institutions and functions among the various links, resulting in a large number of "fragmentation" of food safety supervision departments at present. And the phenomenon of "mix governance" mentioned above is serious. The lack of centralization of food safety regulatory agencies has resulted in the fragmentation of regulatory powers among different departments, and the lack of coordination among different regulatory departments will lead to the "fragmentation" of relations, which will lead to a significant increase in the cost of coordinating the relationship between food safety regulatory departments and promoting cooperation between departments. 


\section{A Feasible Path for Perfecting China's Food Safety Supervision Mechanism}

With the continuous progress and development of society, scientific and technological progress has brought convenience to people's lives, but also increased the risk of food safety. Facing the increasing risk and postmodernism, the current supervision mechanism of Chinese food under the concept of government regulation has been unable to cope, it is necessary to change the value orientation, replace "government regulation" with "social co-governance", and make policy design from three aspects of subject, structure and operation mechanism, and strive to achieve the coupling of policy and value.

\subsection{Main Design: Replacing the "Mixed Governance" with "Multidimensional Co-Governance"}

To improve China's food safety regulatory mechanism, we must first fundamentally change the design of the main body, that is, from the current system of "unitary with the long mix governance" to the "multicultural model" including the government, enterprises and the public. To become a reality, this new subject design must achieve the participation of the participants, fulfill their respective responsibilities, and achieve their participation in food safety governance through institutional arrangements, mechanism innovation, and policy design.

\subsubsection{Government: The Leader in Food Safety Regulation}

Because of the profit-seeking nature of capital and the uneven moral quality of production operators, the "market failure" in the field of food safety is always an objective existence [8]. In this context, the government, as the holder of public power, the distributor of public resources and the defender of public interests, must assume the leading role of food safety supervision. At the same time, food enterprises and the public should fully participate, actively communicate and cooperate to promote the realization of service-oriented government through external pressure [9]. It is necessary to change the government's traditional practice of overwhelming coverage and realize its participation in food safety management through policy formulation and supply. As far as specific policy arrangements are concerned, in terms of market access, the government must change from "certification-based regulation" to "service-oriented regulation"; in terms of inspection and quarantine, the government must improve the existing system, promote social participation, and gradually realize inspection and quarantine. In the aspect of risk management early warning, we can learn from the US "rewarding every report" approach to achieve dynamic and systematic integration; in the aspect of information disclosure, we should replace the closed information transmission mechanism with an open information transmission mechanism; in terms of market exit, it is necessary to promote the construction of a food safety credit system and strictly deal with violations.

\subsubsection{Enterprise: Primary Responsible Person for Food Safety}

As the first link of the industrial chain, as the producers, processors, transporters and sellers of food, food enterprises can be said to be the primary responsibility for safety. Enterprises are most likely to be the producers of unsafe food and the defenders of food safety. Therefore, on the one hand, we should understand the importance of "safeguarding security" to promote the implementation of corporate social responsibility, through the implementation of corporate social responsibility to ensure food safety; improve the enterprise information disclosure system; smooth food safety information exchange channels; standardize the problem of food recall mechanism, reduce its harm to society; but also through the establishment of "food safety fund" to fulfill social responsibility. On the other hand, it is necessary to strengthen the organization degree of food producers, improve the profit distribution mechanism, speed up the application of HACCP, ISO and other production norms in food enterprises, and establish and improve traceability system. Through the improvement of the above safety production guarantee mechanism, the hidden danger of unsafe food can be eliminated from the source.

\subsubsection{The Populace: Direct Beneficiaries of Food Safety}

As the ultimate consumer of food, public life and health are closely related to food safety and are the direct beneficiaries of food safety. In a sense, the public's active participation, rational participation and effective participation in food safety supervision directly determine the effectiveness of supervision. It is hard to imagine that a food safety regulatory mechanism that lacks the direct beneficiary of the public will have a real effect. It is hard to imagine the practical effect of a food safety regulatory mechanism that lacks the direct beneficiary of the public. As far as specific policy design is concerned, first of all, it is necessary to enhance the public's subjective consciousness, awareness of rights protection, civic awareness, cultivate the public spirit, and achieve active participation. Secondly, we should master the knowledge of food safety, enhance the ability of risk self-help through risk education, and realize rational participation with correct channels of participation. Finally, the public should conduct adequate communication on the information disclosure platform, and reach a consensus on reform through public debate, and achieve effective participation through appropriate channels.

\subsection{Architecture Design: Replacing “One-Way \\ One-Dimensional Supervision" with \\ "Multidimensional Network Governance"}

In the food safety supervision network, all subjects participate in consultation and cooperation on an equal footing. No actor has the right to control the actions of other subjects. The absolute power of control under the traditional regulation mode has been lost. All kinds of actors and stakeholders spontaneously solve problems through consultation, bargaining and game [10]. In addition, although the network 
architecture has a common value goal, the value rationality, specific interests, and participation strategies of the participating entities are not the same, and conflicts often occur. For this reason, the operation of the network will mainly focus on the full information sharing of the participating entities, and on this basis, an orderly interest game and interest integration will be realized [11]. Therefore, in order to make the cooperation, communication, interaction and coordination pursued by the food safety supervision network become a reality, we must pay attention to the design and cultivation of the trust mechanism and coordination mechanism.

On the one hand, full mutual trust between the two sides is the basis of cooperation [12]. we should focus on the design of trust mechanism and the cultivation of trust relationship. First, we should restrain the self-interest of the participating subjects by mechanism, carry forward altruism, and promote the realization of public interests with the transfer of mutual interests, so as to promote the construction of the mutual trust relationship among the participants in the food safety supervision network. For example, the government and enterprises should establish and improve various safety information disclosure and disclosure mechanisms, supervision mechanisms, and evaluation mechanisms. As for the specific ways of information disclosure, the network, newspapers, television and other public media are all feasible paths. In addition, the Government can jointly conduct assessments of the food industry, including professional social organizations such as industry associations, and make the results available to the general public for better consumption choices. The second is to promote full interest expression and interest exchange and interest integration among the subjects. The government should unblock the comprehensive channels of interest expression and interest. For example, it can organize and convene representatives of food enterprises, consumers, and representatives of industry associations to open up symposiums in a public forum, and encourage all participating entities to express their full interests and achieve public interest. In addition, as the executive of public power and the authoritative distributor of public resources, the government also needs to regulate the production, processing, transportation and sales behavior of food enterprises through regulatory actions, constrain the public's rational consumption and interest expression behavior, and constrain the effective regulation of social organizations. Guide the development of the industry and conduct full communication, cooperation and consultation with the three as equal partners to build a trust relationship between the government and the enterprise, the public and social organizations. Third, relying on the construction of ethics and morality, we should educate government administrators, enterprise employees and members of social organizations from the perspective of ideology and culture through the construction of mechanism, reshape their professional ethics accomplishment, so that their behavior can adhere to the priority of public interests and follow public values. We should strengthen public morality construction and professional ethics education, strengthen the publicity and education of universal values such as fairness and justice, establish universal values, pursue equal access to safe food, make safe food benefit all the people and become an important component of universal basic welfare, rather than the exclusive products of a few noble classes.

On the other hand, it is necessary to improve the coordination mechanism and strive to promote the coordination of the interests among the participating entities. First, we must perfect the coordination mechanism design of value synergy. Give full play to the leading role of the government in the network and promote the full exchange and interaction of the government's regulatory policies, enterprise security information, public interest demands and professional information of social organizations in the regulatory network through various channels, such as colloquiums, exchanges and network interactive platforms. Under the guidance of public interest value, all participants are led by the government to achieve full consultation. Consequently, we can reach a consensus on governance and form a joint regulatory force. The second is to improve the coordination mechanism design of information sharing. One of the important features of the information society is resource sharing [13]. Government, enterprises, social organizations and other information publishers should make full use of Sina, Sohu, NetEase and other portals with huge and stable visits, publish relevant information, carry out food safety education, and also use Weibo, WeChat, QQ Zone to build interactive communication platform. For local information release, we can use local influential newspapers such as the Times and Evening News to enhance the influence of information. In addition, we can draw lessons from the practices of some European and American countries, paste the results of food safety inspection and assessment directly on the prominent location of the business site for consumers to know, to ensure the accessibility and accessibility of information, thereby avoiding "information monologue" and achieving the effective sharing of information. Third, we should improve the design of coordination mechanism of induction and mobilization. Taking government mobilization as an example, the government first defines a production technology and safety standard for food companies and recommends them for free choice. Subsequently, the government set up an incentive mechanism based on technical standards, and accurately transmitted the information of the incentive mechanism to the enterprise for propaganda and suggestions. After the incentive mechanism has been established, it should be promoted to play its role. The government can flexibly use positive incentives and negative penalties to achieve induction and mobilization.

\subsection{Mechanism Design: Replacing "Piecewise Supervision" with "Collaborative Governance"}

Facing the increasingly severe food safety situation, in order to achieve effective supervision, the most important strategic choice is to break the operating mechanism of 
"segmented supervision-oriented" under the current system, and minimize the distress of departmental interests and "private interests". At the same time, under the guidance of the public interest of "guaranteeing food safety and improving people's well-being", we should reshape the scientific, reasonable and perfect cooperative governance mechanism from many dimensions and levels, and on this basis, continuously improve the governance level of all the participating subjects, including the government, the market, the public and social organizations.

First of all, we should constantly establish and improve the food safety coordination and integration mechanism. To define and differentiate the powers and responsibilities of each participant, to establish a cooperative center composed of multiple participants, make them have the most sufficient resources and the highest power, and to ensure the timeliness, authenticity, validity and sharing of food safety information by using modern science and technology such as electronic information as technical support. Through the full and effective collaborative integration of information and resources, synergies between government departments, between governments and markets, between governments and the public, and social organizations can be achieved. Cooperative governance is fundamentally to remedy the limitations of single-subject governance of market, government and social organizations, and has its unique value in effectively solving the predicament of "one finger cannot pick up a stone" [14]. At the same time, it should be pointed out that China can give full play to the functions of the Food Safety Committee, shape it as the core organ of the collaborative system, and give full play to its collaborative integration role in the system under the premise of clarifying its responsibilities and operating mechanism.

Second, we must constantly improve the early warning mechanism for food safety crisis. While continuously improving domestic R\&D capabilities, we could introduce advanced instruments for food safety inspection and testing in western developed countries, and improve the level of China's food inspection and testing. In addition, on the basis of improving the level of inspection and testing, we should learn from the advanced experience and technology of foreign crisis assessment analysis and early warning, use comprehensive prevention [15] and control technology to accurately prejudge the constraints, development trends and evolution laws of food safety crisis. And apply the food safety synergy integration mechanism, make full use of the portals, magazines and periodicals, evening newspapers and time reports in the country, and timely and accurately release the warning information to protect the people's right to know and eliminate their panic to the crisis. In addition, the diversification and unimpeded access to food safety crisis information should be ensured. For example, we can learn from the practice of "whistle-blowers sharing penalties" in the United States Anti-Fraud Act to establish a system of heavy rewards for whistleblowers. While increasing the penalties for illegal enterprises, a part of the fines will be awarded to the whistle-blowers, which will increase incentives without increasing the financial burden. While strengthening inspection and testing and information collection, we must also strengthen the assessment of security risks. A special safety risk assessment expert group can be set up under the Food Safety Committee. It consists of independent experts and representatives from all walks of life. It is not affiliated with any other organization, and it maintains absolute independence and objectivity. Through full participation and professional intervention, risk assessment can realize the effectiveness and scientificity.

Finally, we must continuously improve and optimize food safety decision-making mechanisms. On the basis of establishing the cooperative integration mechanism of food safety and perfecting the early warning mechanism of food safety crisis, we must break through the limitation of time and space, highlight the participating subjects and links in the space-time sequence with reasonable and effective parallel network flow, make them make decisions within the scope of their core advantages, and finally, under the system synergy mechanism, to achieve effective integration of individual decisions to ensure the fast and effective decision-making. Specifically, before the introduction of major food safety decisions, social opinions must be widely sought, such as using Sina, Sohu, NetEase and other portals to publish policy issues and solicit opinions from the public; on the basis of gathering public opinions, synthesizing expert opinions, formulating alternative policies and plans, and publishing them to the public in time, or taking the form of hearings, widely gathering public opinions and wisdom, and revising and perfecting policies according to the feedback of the public and expert opinions. In this process, the government must change its conception, eliminate the superiority of the high-ranking regulators, pay attention to the public's suggestions, and make targeted changes to enhance the democratic nature of the policy. In addition, it is necessary to highlight the role of experts in the policy development process and enhance the scientific and rational policy. In the process of policy implementation, we should constantly improve the evaluation and feedback mechanism, smooth the channels of public participation, timely amend the policy according to the effect and feedback of policy implementation, and ensure that food safety policy truly reflects the scientific law, public opinion and the needs of the times.

\section{Conclusion}

Through the analysis of China's current "unitary one -way piecewise paradigm" food safety supervision mechanism, it can be seen that there are huge potential safety risks in the main aspects of " multi-agent and chaotic management ", "one-way and one-dimensional" in the structure and "subsection supervision" in the operation, which lead to frequent food safety incidents and have seriously hindered the safety of food. Therefore, in order to satisfy the people's yearning for a better life in the new era, we must first meet the people's need for the most basic guarantee of "safe food". It is necessary to through the improvement, perfection and 
optimization of synergetic integration mechanism, crisis early warning mechanism and public decision-making mechanism, the current food safety supervision mechanism in China can be reshaped and optimized from multiple dimensions and levels, such as information publicity and sharing, inspection and detection technology. Only in this way, the concept of synergetic governance can be finally implemented in the field of food safety governance and the structure of synergetic governance can be guaranteed. In the end, all forces will be gathered to achieve effective participation and ensure effective governance of food safety synergy.

\section{References}

[1] Wen Xiaowei, Yang Chaohui, Chen Yikang, Wen Simei. Forty Years of Reform and Opening-up: Focus Change and Internal Logic of Food Safety in China. Agricultural economic problems. 2018, (10).

[2] Chen Junshi. The Essence of Food Safety. New Rural Technology. 2008 (8): 7.

[3] Zhang Yunhua, Kong Xiangzhi. Game Analysis of Quality and Safety Issues in the Food Supply chain. China Soft Science. 2004, (11).

[4] Li Jing. Research on Subject Relations in Network Governance of Food Safety. Journal of Yunnan Administration College. 2016, (5).

[5] Liu Chang, An Yufa. Study on the Operating Mechanism and Function of FCP in Japanese Food Industry: Based on the Reflection on the "Sanlu" and "Shuanghui" Incidents in China. Journal of Public Administration. 2011, (4).
[6] Wang Caixia. Research on China's Food Safety Regulation under the Disturbance of Local Government. Dalian: Dongbei University of Finance and Economics. 2011.

[7] Zhao Jing. Research on Food Safety Regulation Based on Consumer Cognition. Shandong Social Science. 2018 (12): 171-175.

[8] Chen Jixiu, Liu Zhiyong. Research on the Food Safety Supervision System in China. Chinese Public Administration. 2010, (8).

[9] Li Jing. Cooperative Governance of Food Safety: EU Experience and China's Path. Quest. 2016, (11).

[10] Lou Chengwu, Zhang Jianwei. From Local Government to Local Governance-Study on the Connotation and Model of Local Governance. Chinese Public Administration. 2007, (7).

[11] Yi Yifen. Network Governance: a new framework for public management. Journal of Public Administration. 2007, (1).

[12] Li Jing. Autonomous Subject, Mutual Trust Mechanism and Dialogue Mode: the Governance Logic of the Cooperative Society. Thinking. 2017, 43 (6).

[13] Qin Shuiruo. Six Trends in the Development of Administrative Power in the Information Age. Chinese Public Administration. 2005, (12).

[14] Liu Weizhong. The Value and Challenge of Collaborative Governance. Journal of Jiangsu Administration Institute. 2012, (5).

[15] Sha Yongzhong, Jie Zhiyuan. On the Coordinated Management of Public Crisis. Chinese Public Administration. 2010, (4). 